\title{
Role of the Peripheral Sympathetic Innervations in Controlling Cerebral Blood Flow after the Transection of Bilateral Superior Cervical Sympathetic Ganglia Two Weeks Later
}

\author{
Cheng-Ta Hsieh ${ }^{1,2}$, Shinn-Zong Lin ${ }^{3}$, Ming-Ying Liu' ${ }^{1}$ \\ ${ }^{1}$ Department of Neurological Surgery, Tri-Service General Hospital, National Defense \\ Medical Center, Taipei, China \\ ${ }^{2}$ Division of Neurosurgery, Department of Surgery, Sijhih Cathay General Hospital, \\ New Taipei, China \\ ${ }^{3}$ Division of Neurosurgery, Department of Surgery, China Medical University Hospital, \\ Taichung, Taiwan, China \\ E-mail: nogor@mail2000.com.tw \\ Received March 30, 2011; revised May 5, 2011; accepted May 10, 2011.
}

\begin{abstract}
Background: Cerebral blood vessels are mainly supplied by sympathetic nerves arising from the superior cervical ganglia and cerebral blood volume may be influenced by bilateral superior cervical ganglionectomy (SCG). Various stages of cerebral blood volume changes depended on the time following bilateral excision of SCG. In this study, we emphasize the subacute effect (two weeks) on the local cerebral blood flow (LCBF). Material and Methods: Sprague-Dawley rats weighing 250 - $400 \mathrm{gm}(n=20)$ were selected into two groups. Under the ambient temperature $20^{\circ} \mathrm{C}$, the first group animals $(n=10)$ received sham operation and the other group animals $(n=10)$ underwent bilateral SCG. The LCBF and $\mathrm{O}_{2}$ delivery of 14 brain structures were measured for each animal by the use of ${ }^{14} \mathrm{C}$-iodoantipyrine technique two weeks after the operation. Results: The average of LCBF was decreased from $150 \mathrm{ml} / 100 \mathrm{gm} / \mathrm{min}$ to $129 \mathrm{ml} / 100 \mathrm{gm} / \mathrm{min}$ after bilateral SCG. Only the LCBF at basal ganglia was increased from $108 \mathrm{ml} / \mathrm{min} / 100 \mathrm{~g}$ in the sham-operated group to $118 \mathrm{ml} / \mathrm{min} / 100 \mathrm{~g}$ in the SCG group. A mean of $14 \%$ reduction of LCBF was estimated. In 14 brain structures, the delivery amount of $\mathrm{O}_{2}$ was all decreased, except in basal ganglia. However, these changes of LCBF and the delivery amount of $\mathrm{O}_{2}$ at these 14 brain structures did not reach the significant differences. Conclusions: The present results show that chronic effect (two weeks) of bilateral SCG on LCBF was not only in a decrease of the LCBF, but also a decrease of local cerebral $\mathrm{O}_{2}$ delivery. However, the changes didn't show the significant differences.
\end{abstract}

Keywords: Local Cerebral Blood Flow, Cervical Ganglia, Ganglionectomy

\section{Introduction}

The relationship between autonomic regulation and cerebral blood flow (CBF) has long been a subject of considerable interest in studying the mechanisms of neurovascular disorders such as hypertensive encephalopathy, migraine and syncope [1]. Cerebral blood vessels are mainly supplied by sympathetic nerves arising from the superior cervical ganglia, and the sympathetic nerves, heterogeneously distributed throughout the cere- brocortex [2,3]. Although nervous stimulation or adrenergic agonists lead to vasoconstriction, superior cervical ganglionectomy (SCG) or adrenergic antagonists do not usually affect regional CBF $[4,5]$. "Microregional" differences in the cerebrocortex without decreasing global and regional blood flow, resulted from limit flow and/or decrease red cell velocity, has been hypothesized [6]. The subacute effect of SCG on cerebral microcirculation remains obscure. In this study, we evaluate local cerebral blood flow (LCBF) and the delivery amount of $\mathrm{O}_{2}$ at 14 
brain structures in experimental rats underwent bilateral SCG.

\section{Material and Methods}

Male Sprague-Dawley rats weighing 250 to 400 gm were used for these experiments. These animals were fasted for approximately 12 hours before surgery.

\subsection{Surgical Techniques}

The rats were anesthetized with $3 \%$ halothane for $2-4$ minutes until they were calm down. The anesthesia was continued with $1.5 \%$ halothane in nitrous oxide $(70 \%)$ and oxygen (30\%) for the period of surgery. The femoral artery and femoral vein were catheterized on both sides of the animals with polyethylene tube (PE-50). The surgical wounds were covered with xylocaine jelly. A plaster cast was fitted from midthorax to midthigh to immobilize the hind limbs and protect the catheters. Then the anesthesia was stopped and the animals were allowed to recover the consciousness.

\subsection{Experimental Design}

The rats were exposed in normal condition (ambient temperature $20^{\circ} \mathrm{C}$ ) and their physiological condition was assessed by measurement of hematocrit (Hct), hemoglobin $(\mathrm{HgB}), \mathrm{pH}, \mathrm{pCO}_{2}, \mathrm{pO}_{2}$, volume and saturation of $\mathrm{O}_{2}$, systolic blood pressure (SBP), diastolic blood pressure (DBP), mean arterial blood pressure (MBP), pulse rate (PR), weight, and plasma glucose level. Total 20 male Sprague-Dawley rats were divided into two groups: Group A $(n=10)$ as the control group underwent sham operation. Group B $(n=10)$ received bilateral superior cervical ganglionectomy. Local cerebral blood flow and $\mathrm{O}_{2}$ delivery were measured post each operation. Superior cervical ganglionectomy was performed as: the salivary glands were exposed through sublingular incision in the neck and each superior cervical ganglion was identified at the bifurcation of the common carotid artery beside the trachea. The ganglia were totally removed en bloc from both sides. Sham operation received the same procedure as above except the removal of SCG. After recovering from the anesthesia, the rats were put in a cage with food as usual. Two weeks later, the rats were re-anesthetized for measurement of LCBF.

\subsection{Measurement of Local Cerebral Blood Flow}

The LCBF was measured by the ${ }^{14} \mathrm{C}$-iodoantipyrine (IAP) technique developed by Sakurada et al. [7], as modified by Otsuka et al. [8]. Before beginning IAP infusion, a single extracorporeal arteriovenous (AV) shunt was formed by shortening and connecting the femoral artery and vein catheters on one side with a $3-\mathrm{cm}$ length of silicone rubber tubing. At the beginning of the experimental period $(t=0)$, an intravenous infusion of approximately $50 \mathrm{uCi}$ of ${ }^{14} \mathrm{C}-\mathrm{IAP}$ in $1 \mathrm{ml}$ saline was started using a variable speed infusion pump. The rate of infusion was increased during the experiment according to a schedule that yielded a linearly rising concentration of IAP in the blood. Series arterial blood sampling was performed (every $5 \mathrm{sec}$ starting at $t=0$ ) by puncturing the extracorporeal AV loop with a 22-gauge needle on a plungerless syringe and collecting $60 \sim 80 \mu \mathrm{l}$ blood over the next $2-4 \mathrm{sec}$. The rats were decapitated at $t=30 \mathrm{sec}$, and their brains were quickly removed., frozen in 2-methylbutane cooled to $-45^{\circ} \mathrm{C}$, and stored in a plastic bag at $-80^{\circ} \mathrm{C}$ until the time of sectioning.

Plasma ${ }^{14} \mathrm{C}$-radioactivity was assayed by beta counting. The frozen brain was cut into a series of $20 \mu \mathrm{m}$ thick sections in a cryostat at $-20^{\circ} \mathrm{C}$ starting at the area postrema, which lies at the caudal end of the fourth ventricle. Selected brain sections from inferior collicullus, superior collicullus, midbrain, occipital cortex, pons, medulla oblongata, hippocampus, hypothalamus, thalamus, corpus callosum, temporal cortex, frontal cortex, basal ganglia, sensorimotor cortex, cerebellar vermis were dried and placed in X-ray cassettes along with sets of previously calibrated ${ }^{14} \mathrm{C}$ standards. Many of the areas were selected because they had been included in the reports of Kadekaro et al. [9] and our previous study [10]. Un-exposed X-ray film (Kodak SB-5) was placed over the brain section and standards. After approximately 12 days of exposure, the films were developed. The entire autoradiograms were analyzed for radioactivity using an image processing system (MCID, Imaging Research, St. Catharings, Canada). The optical density values were converted to tissue reactivity using the Kety-Sokoloff equation [7].

\subsection{Measurement of $\mathrm{O}_{2}$ Delivery}

Adjacent frozen samples from fourteen brain regions were immediately used to determinate arterial and venous $\mathrm{O}_{2}$ saturation. Detail techniques have been published previously [11]. Briefly, $20 \mu \mathrm{m}$ sections were obtained on themicrotome-cryostat at $-35^{\circ} \mathrm{C}$ under a $\mathrm{N}_{2}$ atmosphere. The sections were transferred to precooled glass slides and covered with degassed silicone oil and a cover slip. The slides were placed on a microspectrophotometer fitted with an $\mathrm{N}_{2}$-flushed cold stage to obtain readings of optical densities at 568, 560, and $506 \mathrm{~nm}$. This three-wavelength method corrects for the light scattering in the frozen blood. Only vessels in the transverse 
section were studied so that the path of light traversed only the blood, Readings were obtained to determine $\mathrm{O}_{2}$ saturation in these regions. The $\mathrm{O}_{2}$ content of blood was determined by multiplying the percent $\mathrm{O}_{2}$ saturation by the hemoglobin concentration times 1.36.

\subsection{Statistics}

All data was presented with means \pm SEM and statistically calculated by unpaired, two-tails $t$ test.

\section{Results}

Hemodynamic and physiological data including plasma glucose level, HCT, $\mathrm{pH}$, pulse rate, weight, systolic blood pressure, diastolic blood pressure, mean blood pressure in two groups revealed no significant difference (Table 1). According to the relevant data of blood gas, a significant hyperoxemia ( $\mathrm{pO}_{2}$ from 87.1 to 97 torrs, $p<$ 0.05) was demonstrated, but the $\mathrm{pCO}_{2}$, the volume of $\mathrm{O}_{2}$ and the saturation of $\mathrm{O}_{2}$ did not reach the significant differences.

LCBF at 14 brain structures was presented in Table 2. Only the LCBF at basal ganglia was increased from 108 $\mathrm{ml} / \mathrm{min} / 100 \mathrm{~g}$ in the SCG group to $118 \mathrm{ml} / \mathrm{min} / 100 \mathrm{~g}$ in the sham-operated group. The others 13 brain structures showed a decreased level of LCBF. The average of LCBF was $150 \mathrm{ml} / \mathrm{min} / 100 \mathrm{~g}$ in the sham-operated group and $129 \mathrm{ml} / \mathrm{min} / 100 \mathrm{~g}$ in the SCG group. A mean of $14 \%$ reduction of $\mathrm{LCBF}$ was found at 14 brain structures. However, these changes of LCBF at these 14 brain structures did not reach the significant differences.

The delivery amount of $\mathrm{O}_{2}$ was also measured at 14 brain structures and summarized in Table 3. In 14 brain structures, the delivery amount of $\mathrm{O}_{2}$ was all decreased, except in basal ganglia. The differences in the delivery amount of $\mathrm{O}_{2}$ between sham-operated and symphathectomized group was not significantly meaningful in these 14 brain structures.

\section{Discussion}

Sympathetic nerves supply different parts of the cerebrovascular system including the main pial arteries at the base of the brain, the pial arterial and venous systems of the convexities, and parts of the intracerebral (parenchymal) vascular system [12]. Using the techniques of immunofluorescence and histofluorescence, cerebral vessels have been proved to be innerved by peripheral sympathetic nervous system, mainly arising from the ipsilateral

Table 1. Hemodynamic and physiological data in experimental rats under sham operation and SCG.

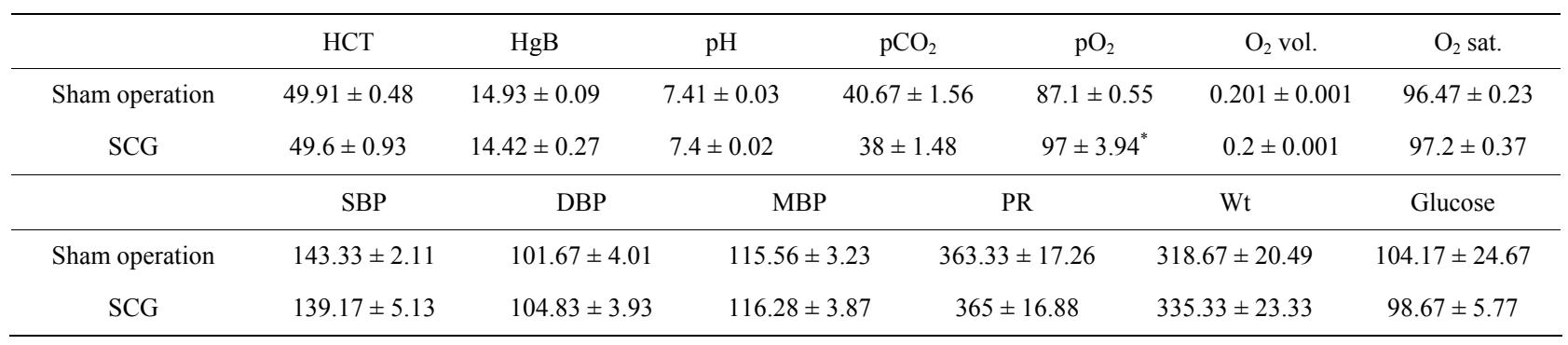

*: significant difference between sham operation and SCG group in room temperature (two tailed, unpaired-t test), $\mathrm{P}<0.05$, values are means $\pm \mathrm{SEM}$. HCT: hematocrit; $\mathrm{HgB}$ : hemoglobin; $\mathrm{pH}, \mathrm{pCO}_{2}, \mathrm{pO}_{2}$ : blood gas; $\mathrm{O}_{2}$ vol.: $\mathrm{O}_{2}$ volume; $\mathrm{O}_{2}$ sat.: $\mathrm{O}_{2}$ saturation; SBP: systolic blood pressure; DBP: diastolic blood pressure; MBP: mean arterial blood pressure; PR: pulse rate; Wt: weight.

Table 2. Local cerebral blood flow ( $\mathrm{ml} / \mathrm{min} / \mathbf{1 0 0 \mathrm { gm } )}$ at 14 brain structures in rats underwent sham operation and SCG in room temperature.

\begin{tabular}{|c|c|c|c|c|c|c|c|c|}
\hline & \multicolumn{8}{|c|}{ Forebrain } \\
\hline & $\mathrm{FC}$ & SMC & $\mathrm{TC}$ & $\mathrm{OC}$ & BG & HIP & Thalamus & Нypo \\
\hline Sham operation & $234 \pm 38$ & $239 \pm 40$ & $125 \pm 23$ & $190 \pm 27$ & $108 \pm 22$ & $119 \pm 14$ & $151 \pm 15$ & $120 \pm 15$ \\
\hline \multirow[t]{3}{*}{ SCG } & $191 \pm 15$ & $203 \pm 13$ & $107 \pm 12$ & $182 \pm 17$ & $118 \pm 21$ & $95 \pm 6$ & $133 \pm 9$ & $93 \pm 8$ \\
\hline & \multicolumn{4}{|c|}{ Rostral hindbrain } & \multicolumn{4}{|c|}{ Caudal hindbrain } \\
\hline & $\mathrm{SC}$ & \multicolumn{2}{|c|}{ IC } & Midbrain & Pons & \multicolumn{2}{|c|}{ Medulla } & Vermis \\
\hline Sham operation & $166 \pm 25$ & \multicolumn{2}{|c|}{$155 \pm 30$} & $133 \pm 14$ & $117 \pm 12$ & \multicolumn{2}{|c|}{$102 \pm 10$} & $135 \pm 17$ \\
\hline SCG & $126 \pm 8$ & \multicolumn{2}{|c|}{$138 \pm 8$} & $103 \pm 7$ & $117 \pm 27$ & \multicolumn{2}{|c|}{$83 \pm 4$} & $108 \pm 6$ \\
\hline
\end{tabular}

Values are means \pm SEM. FC: frontal cortex; SMC: sensorimotor cortex; TC: temporal cortex; OC:occipital cortex; BG: basal ganglia; HIP: hippocampus; HYPO: hypothalamus; SC: superior colliculus; IC: inferior colliculus. 
Table 3. $\mathrm{O}_{2}$ delivery $(\mathrm{ml} / \mathrm{min} / 100 \mathrm{gm})$ at 14 brain structures in rats underwent sham operation and SCG in room temperature.

\begin{tabular}{|c|c|c|c|c|c|c|c|c|}
\hline \multirow[b]{3}{*}{ Sham operation } & \multicolumn{8}{|c|}{ Forebrain } \\
\hline & $\mathrm{FC}$ & $\mathrm{SMC}$ & $\mathrm{TC}$ & $\mathrm{OC}$ & BG & HIP & Thalamus & Нуро \\
\hline & $47 \pm 8$ & $48 \pm 8$ & $25 \pm 4$ & $38 \pm 5$ & $22 \pm 4$ & $24 \pm 3$ & $30 \pm 3$ & $24 \pm 3$ \\
\hline \multirow[t]{3}{*}{ SCG } & $38 \pm 3$ & $40 \pm 2$ & $21 \pm 2$ & $36 \pm 3$ & $23 \pm 4$ & $19 \pm 1$ & $26 \pm 2$ & $18 \pm 2$ \\
\hline & \multicolumn{4}{|c|}{ Rostral hindbrain } & \multicolumn{4}{|c|}{ Caudal hindbrain } \\
\hline & $\mathrm{SC}$ & \multicolumn{2}{|c|}{ IC } & Midbrain & Pons & \multicolumn{2}{|c|}{ Medulla } & Vermis \\
\hline Sham operation & $33 \pm 5$ & \multicolumn{2}{|c|}{$31 \pm 6$} & $27 \pm 3$ & $24 \pm 2$ & \multicolumn{2}{|c|}{$20 \pm 2$} & $27 \pm 3$ \\
\hline SCG & $25 \pm 2$ & \multicolumn{2}{|c|}{$27 \pm 2$} & $20 \pm 1$ & $23 \pm 5$ & \multicolumn{2}{|c|}{$17 \pm 1$} & $21 \pm 1$ \\
\hline
\end{tabular}

Values are means \pm SEM. FC: frontal cortex; SMC: sensorimotor cortex; TC: temporal cortex; OC:occipital cortex; BG: basal ganglia; HIP: hippocampus; HYPO: hypothalamus; SC: superior colliculus; IC: inferior colliculus.

superior cervical ganglion [13]. These nerve fibers are distributed mainly in rostral areas of the brain and heterogeneously distributed to cortical vessels to the level of arterioles [5]. The innervation also provides a protective mechanism for brain to insure an adequate $\mathrm{O}_{2}$ supply to caudal regions under hypoxic conditions by limiting flow to cortical areas [6].

Several studies about sympathetic influences on cerebral vessels have been discussed, especially in SCG, by measuring the cerebral blood volume $(\mathrm{CBV})$ and regional CBF. Eklof et al. discovered CBF reduced about $30 \%$ in monkeys undergo bilateral SCG within 2 weeks but the same results were not observed by Waltz et al in the cat after monolateral SCG $[14,15]$. Several experimental studies revealed the various stages of CBV depended on the time following bilateral SCG $[12,16,17]$. In serial mice studies, Edvinsson et al. found, compared with sham-operated controls, CBV was decreased to a level $15 \%$ to $28 \%$ below the control values twelve hours after SCG, increased to a level $15 \%$ to $34 \%$ above the control values one day later, and returned to normal range within only one week $[12,16]$. He hypothesized the vasoconstriction was caused by norepinephrine leakage from the degenerating nerves shortly after operation; vasodilatation resulted from a consequence of disappearance of the transmitter one day later; and normalization of vascular tone was caused by supersensitivity of denervated vascular receptors to circulating catecholamines in chronic phase [12].

However, in the studies emphasized on the long term effects ( 8 - 10 weeks) of unilateral SCG on non-anesthetized rabbits, Aubineau et al. [18], found a mean of 17\% reduction of $\mathrm{CBF}$ compared to the heterolateral cortex. This phenomenon was observed from 8 to 30 days after the operation. Intravenous infusion of noradrenaline did not significantly modify CBF in both hemispheres. There were no signs of supersensitivity to catecholamines. They concluded that, as in the peripheral circulation, chronic sympathectomy affects the equilibrium of the vascular smooth muscle fibers, but that circulating amines play no compensatory role in the cerebral circulation because of the blood-brain barriers. So the reduction of CBF could be attributed to many factors after sympathectomy: decrease in the thickness of the turnica media of the cerebral vessels [19], a modification of membrane mechanisms of the smooth muscle fibers [20], depolarization without any possible modification in the threshold of excitability, a hypersensitivity to calcium ion, and possible metabolic changes revealed by a decrease in sodium-potassium-adenosine triphosphatase activity and modification in the level of adenosine triphosphate [18]. Suppression of the whole cervical sympathetic innervation could also result in a reduction in pineal gland activity [21], alterations in the numerous neuroendocrine systems [22], or a modification in the activity of the carotid sinus [23]. Some of these phenomena may modify CBF and CBV in the long term.

In our present study, two weeks postoperatively, the bilateral SCG rats displayed a mean of $14 \%$ reductive level of LCBF as compared to those of the sham-operated rats. In the 14 brain structure, the LCBF was all decreased, except in the basal ganglia. It showed the subacute effect of bilateral SCG was not only in the CBF, but also in the LCBF. The delivery amount of $\mathrm{O}_{2}$ was also decreased in these regions. Our results were compatible with previous reports $[11,18]$. Based on these results, we could conduct the study to investigate the further effect of bilateral SCG in the rats with heat stroke.

\section{Conclusions}

Although the change of LCBF and local cerebral $\mathrm{O}_{2}$ delivery in the 14 brain structure didn't show the significant differences, our present results show that subacute effect (two weeks) of bilateral SCG on CBF was not only in a decrease of LCBF, but also a decrease of local cerebral $\mathrm{O}_{2}$ delivery. About $14 \%$ decrease level of LCBF was 
observed

\section{References}

[1] Y. H. Sohn, "Cerebral Hemodynamic Changes Induced by Sympathetic Stimulation Tests," Yonsei Medical Journal, Vol. 39, No. 4, 1998, pp. 322-327.

[2] D. W. Busija, "Sustained Cerebral Vasoconstriction during Bilateral Sympathetic Stimulation in Anesthetized Rabbits", Brain Research, Vol. 345, No. 2, 1985, pp. 341-344. doi:10.1016/0006-8993(85)91013-3

[3] L. Edvinsson, "Neurogenic Mechanisms in the Cerebrovascular Bed. Autonomic Nerves, Amine Receptors and Their Effects on Cerebral Blood Flow," Acta physiologica Scandinavica. Supplementum, Vol. 427, 1975, pp. $1-35$.

[4] S. Sadoshima, K. Fujii, K. Kusuda, O. Shiokawa, H. Yao and S. Ibayashi, "Importance of Bilateral Sympathetic Innervation on Cerebral Blood Flow Autoregulation in the Thalamus", Brain Research, Vol. 413, No. 2, 1987 , pp. 297-301. doi:10.1016/0006-8993(87)91020-1

[5] H. M. Wei, A. K. Sinha and H. R. Weiss, "Cervical Sympathectomy Reduces the Heterogeneity of Oxygen Saturation in Small Cerebrocortical Veins," Journal of Applied Physiology, Vol. 74, No. 4, 1993, pp. 1911-1915.

[6] H. M. Wei, W. Y. Chen, A. K. Sinha and H. R. Weiss, "Effect of Cervical Sympathectomy and Hypoxia on the Heterogeneity of $\mathrm{O}_{2}$ Saturation of Small Cerebrocortical Veins", Journal of Cerebral Blood Flow \& Metabolism, Vol. 13, No. 2, 1993, pp. 269-275. doi: $10.1038 /$ jcbfm. 1993.33

[7] O. Sakurada, C. Kennedy, J. Jehle, J. D. Brown, G. L. Carbin and L. Sokoloff, "Measurement of Local Cerebral Blood Flow with Iodo [14C] Antipyrine", American Journal of Physiology, Vol. 234, No. 1, 1978, pp. H5966.

[8] T. Otsuka, L. Wei, V. R. Acuff, A. Shimizu, K. D. Pettigrew, C. S. Patlak, "Variation in Local Cerebral Blood Flow Response to High-Dose Pentobarbital Sodium in the Rat", American Journal of Physiology, Vol. 261, No. 1-2, 1991, pp. H110-120.

[9] M. Kadekaro, H. E. Savaki, F. A. Kutyna, L. Davidsen, L. Sokoloff, "Metabolic Mapping in the Sympathetic Ganglia and Brain of the Spontaneously Hypertensive Rat", Journal of Cerebral Blood Flow \& Metabolism, Vol. 3, No. 4, 1983, pp. 460-467. doi:10.1038/jcbfm.1983.72

[10] S. Z. Lin, N. Sposito, S. Pettersen, L. Rybacki, E. McKenna, K. Pettigrew, "Cerebral Capillary Bed Structure of Normotensive and Chronically Hypertensive Rats," Microvascular Research, Vol. 40, No. 3, 1990, pp. 341-357. doi:10.1016/0026-2862(90)90032-M

[11] M. T. Lin and S. Z. Lin, "Decentralization of Superior Cervical Ganglia Attenuates Heat Stroke Formation in Rabbits," The Chinese Journal of Physiology, Vol. 33, No. 3, 1990, pp. 247-253.

[12] L. Edvinsson, K. C. Nielsen, C. Owman, K. A. West, "Evidence of Vasoconstrictor Sympathetic Nerves in
Brain Vessels of Mice," Neurology, Vol. 23, No. 1, 1973, pp. 73-77.

[13] M. E. Raichle, B. K. Hartman, J. O. Eichling and L. G. Sharpe, "Central noradrenergic regulation of cerebral blood flow and vascular permeability", Proceedings of the National Academy of Sciences of the United States of America, Vol. 72, No. 9, 1975, pp. 3726-3730. doi:10.1073/pnas.72.9.3726

[14] B. Eklof, D. H. Ingvar, E. Kagstrom and T. Olin, "Persistence of Cerebral Blood Flow Autoregulation Following Chronic Bilateral Cervical Sympathectomy in the Monkey", Acta Physiologica Scandinavica, Vol. 82, No. 2, 1971, pp. 172-176. doi:10.1111/j.1748-1716.1971.tb04956.x

[15] A. G. Waltz, T. Yamaguchi and F. Regli, "Regulatory Responses of Cerebral Vasculature after Sympathetic Denervation," American Journal of Physiology, Vol. 221, No. 1, 1971, pp. 298-302.

[16] L. Edvinsson, K. C. Nielsen, C. Owman, K. A. West, "Sympathetic Adrenergic Influence on Brain Vessels as Studied by Changes in Cerebral Blood Volume of Mice," European Neurology, Vol. 6, No. 1, 1971, pp. 193-202. doi: $10.1159 / 000114492$

[17] S. H. Tsai, S. Z. Lin and C. J. Shih, "Effects of Pre-Ganglionic Decentralization or Post-Ganglionic Excision of the Superior Cervical Ganglia on Brain Edema and Heat Stroke in Rats," Proceedings of the National Science Council, Republic of China. Part B, Vol. 8, No. 4, 1984, pp. 335-340.

[18] P. Aubineau, A. M. Reynier-Rebuffel, C. Bouchaud, O. Jousseaume, J. Seylaz, "Long-Term Effects of Superior Cervical Ganglionectomy on Cortical Blood Flow of Non-Anesthetized Rabbits in Resting and Hypertensive Conditions," Brain Research, Vol. 338, No. 1, 1985, pp. 13-23. doi:10.1016/0006-8993(85)90243-4

[19] R. D. Bevan, H. Tsuru and J. A. Bevan, "Cerebral Artery Mass in the Rabbit is Reduced by Chronic Sympathetic Denervation," Stroke, Vol. 14, No. 3, 1983, pp. 393-396. doi:10.1161/01.STR.14.3.393

[20] O. Aprigliano, "Neural Influences and Norepinephrine Sensitivity in the Rat Portal Vein", Fed Proc, Vol. 42, No. 2, 1983, pp. 257-262.

[21] M. A. Luchelli-Fortis, F. J. Stefano and C. J. Perec, "Degeneration Activity of the Pineal Gland after Sympathetic Denervation," Naunyn-Schmiedeberg's Archives of Pharmacology, Vol. 321, No. 4, 1982, pp. 298-301. doi:10.1007/BF00498517

[22] D. P. Cardinali, M. I. Vacas, P. V. Gejman, M. A. Pisarev, M. Barontini and R. J. Boado, "The Sympathetic Superior Cervical Ganglia as 'Little Neuroendocrine Brains'," Acta physiologica latino americana, Vol. 33, No. 3, 1983, pp. 205-221.

[23] K. Koizumi and A. Sato, "Influence of Sympathetic Innervation on Carotid Sinus Baroreceptor Activity", American Journal of Physiology, Vol. 216, No. 2, 1969, pp. 321-329. 